\title{
The effect of moderate exercise on postprandial glucose homeostasis in NIDDM patients
}

\author{
J J .S. L arsen ${ }^{1,3}$, F. D ela ${ }^{1,3}$, M . K Jær ${ }^{2,3}$, H . G albo ${ }^{1,2,3}$ \\ ${ }^{1}$ Department of Medical Physiology, The Panum Institute, Copenhagen, Denmark \\ ${ }^{2}$ Department of Rheumatology, Bispebjerg Hospital, Copenhagen, Denmark \\ ${ }^{3}$ The Copenhagen Muscle Research Centre, Rigshospitalet, Denmark
}

Summary The influence of exercise on glycaemia in the post-prandial state was studied for the first time in non-insulin-dependent diabetic (NIDDM) patients. Meal-induced glucose responses were followed for $8 \mathrm{~h}$ in 9 diet-treated patients with NIDDM. Subjects consumed a standardized breakfast and $4 \mathrm{~h}$ later a standardized lunch. They were studied in the resting state (control day (CD)) and on another day $45 \mathrm{~min}$ of bicycle exercise $\left(53 \pm 2 \% \dot{\mathrm{V}}_{\mathrm{O}_{2}} \max (\right.$ mean \pm SEM) $)$ was performed 45 min after breakfast (exercise day (ED)). On day 3 (diet day (DD)), the breakfast meal was reduced corresponding to the extra energy expenditure during the exercise period on ED. Responses were calculated as areas under the plasma concentration curve (AUC) during $4 \mathrm{~h}$ after either breakfast (B-AUC) or lunch (L-AUC). B-AUC for glucose was identical on ED $(215 \pm 63 \mathrm{mmol} / \mathrm{l}$. $240 \mathrm{~min})$ and $\mathrm{DD}(219 \pm 60 \mathrm{mmol} / \mathrm{l} \cdot 240 \mathrm{~min})$ and on these days lower $(p<0.05)$ than on $C D$ $(453 \pm 78 \mathrm{mmol} / \mathrm{l} \cdot 240 \mathrm{~min})$. L-AUC for glucose on $\mathrm{CD}$, ED and DD did not differ significantly.
B-AUCs for both insulin and C-peptide were also significantly lower on ED and DD as compared to CD (Insulin: $31337 \pm 8682,26092 \pm 6457$ and $47649 \pm$ $15046 \mathrm{mmol} / \mathrm{l} \cdot 240 \mathrm{~min}$, respectively. C-peptide: $99 \pm$ $19,104 \pm 26$ and $195 \pm 31 \mathrm{pmol} / \mathrm{ml} \cdot 240 \mathrm{~min}$, respectively). Rate of appearance ( $\mathrm{Ra}$ ) for glucose was unaffected by exercise whereas rate of disappearance $(\mathrm{Rd})$ increased significantly. No differences in $\mathrm{Ra}$ or $\mathrm{Rd}$ were observed after lunch. In conclusion, postprandial exercise of moderate intensity decreases glycaemia and plasma insulin levels after breakfast in NIDDM patients, but this effect does not persist during and after the following lunch meal. Reduction of breakfast caloric intake has the same effect on postprandial glycaemia and insulin secretion as an equivalent exercise-induced increase in caloric expenditure. [Diabetologia (1997) 40: 447-453]

Keywords Insulin sensitivity, physical activity, insulin, C-peptide, non-esterified fatty acids; glycerol, glucose turnover.
Received: 4 October 1996 and in revised form: 18 December 1996

Corresponding author: J.J.S. Larsen, M.D., Department of Medical Physiology, The Panum Institute, Blegdamsvej 3, DK-2200 Copenhagen N, Denmark

A bbreviations: CD, Control day; ED, exercise day; DD, diet day; $\mathrm{V}_{\mathrm{O}_{2}}$ max, maximal oxygen uptake; $\mathrm{Ra}$, rate of appearance; $\mathrm{Rd}$, rate of disappearance; AUC, area under curve; B-AUC, area under curve $4 \mathrm{~h}$ after start of breakfast; L-AUC, Area under curve $4 \mathrm{~h}$ after start of lunch; $3-\left[{ }^{3} \mathrm{H}\right]$-glucose, tritiated glucose in carbon position three; NIDDM, non-insulin-dependent diabetes mellitus.
It is generally accepted that the metabolic regulation of non-insulin-dependent diabetic (NIDDM) patients is influenced by their diet and physical activity. In the postabsorptive state exercise of moderate intensity has been shown to decrease plasma glucose concentrations and is followed by an increase in insulin sensitivity [1-5]. Essentially these facts provide the rationale for using exercise as a tool in the treatment of NIDDM. However, during daily life physical exercise is mostly taken in the postprandial rather than in the postabsorptive state. In patients with insulin-dependent diabetes this fact has led to studies of the effect of exercise on postprandial glycaemia [4]. It was found that in patients treated with fixed 
amounts of insulin, exercise reduced glycaemia [6]. However, these findings do not necessarily apply to patients with NIDDM as endogenous insulin secretion may be reduced by exercise [7]. We therefore studied the effect of a prolonged submaximal exercise bout on the postprandial glycaemic excursions and glucose turnover after a standardized breakfast meal and a following standardized lunch meal. In addition, we studied whether any effect of exercise could be mimicked by reducing caloric intake during breakfast with an amount equivalent to the caloric expenditure inherent in exercise.

\section{Materials and methods}

Subjects. Nine sedentary males (fasting plasma glucose concentrations: $8.8 \pm 0.7 \mathrm{mmol} / \mathrm{l}$ (mean $\pm \mathrm{SEM}) ; \mathrm{HbA}_{1 \mathrm{c}}: 7.1 \pm 0.2 \%$; age: $60 \pm 2$ years; weight: $86 \pm 4 \mathrm{~kg}$; BMI: $29 \pm 1 \mathrm{~kg} \cdot \mathrm{m}^{-2}$; and $\dot{\mathrm{V}}_{\mathrm{O}_{2}} \max : 29 \pm 1 \mathrm{ml} \cdot \mathrm{min}^{-1} \cdot \mathrm{kg}^{-1}$ ) who met the current criteria of the World Health Organization classification of diabetes mellitus (fasting venous plasma glucose $>7.8 \mathrm{mmol} / 1$, and/or plasma glucose $>11.1 \mathrm{mmol} / 1120 \mathrm{~min}$ after an oral intake of $75 \mathrm{~g}$ glucose) participated in the study.

All subjects were normotensive and had normal renal, hepatic, cardiac and neurological functions as assessed by clinical examination, exercise ECG and standard blood screening. The subjects were treated by diet alone, and none of them were engaged in a regular exercise programme. They gave informed consent to participate in the study, which was approved by the municipal ethical committee for Copenhagen and Frederiksberg.

P re-study evaluation. One laboratory session was used to carefully determine the relationship between work load and oxygen consumption $\left(\dot{\mathrm{V}}_{\mathrm{O}_{2}}\right)$ 7-14 days before the first metabolic study. For each subject graded exercise was carried out to exhaustion on a bicycle ergometer (Monark, Varberg, Sweden). At least five different work loads at a pedal frequency of $60 \mathrm{rev} / \mathrm{min}$ were used. Oxygen uptake was measured by the Douglas bag method and individual $\dot{\mathrm{V}}_{\mathrm{O}_{2}} \max$ was defined by the 'leveling-off' criterion (e.g. no significant further increase in $\dot{\mathrm{V}}_{\mathrm{O} 2}$ with increasing exercise intensity). From these data, the work load requiring $50 \%$ of the subject's individual $\dot{\mathrm{V}}_{\mathrm{O}_{2}}{ }^{\text {max }}$ was estimated.

Experimental protocol. The study included 3 separate days of investigation: a control day (CD), an exercise day (ED) and a diet day (DD), only 7 of the 9 subjects participated in this experiment. However, this subgroup had values similar to those of the whole group on $\mathrm{CD}$ and ED, $\mathrm{p}>0.05)$. Experiments were separated by 14-18 days. CD and ED were done in randomised order and followed by DD. The subjects arrived in the laboratory at 06.45 hours after an overnight fast, were weighed, and put to bed. One cannula was inserted in a dorsal antebrachial vein for primed infusion of $3-\left[{ }^{3} \mathrm{H}\right]$-glucose $(\mathrm{New}$ England Nuclear, by Isotopapoteket, Copenhagen, Denmark; specific activity $\left.1.5 \pm 0.1 \mu \mathrm{Ci} \cdot \mathrm{mg}^{-1}\right)$. A bolus adjusted to the individual basal plasma glucose concentration $(42.4 \pm 3.2 \mu \mathrm{Ci})$ was given and followed by $0.29 \mu \mathrm{Ci} / \mathrm{min}$ [8]. On DD only four subjects had labelled glucose infused. Another cannula was inserted in the contralateral arm in the retrograde direction in a dorsal hand vein for drawing of arterialized blood. To arterialize the blood the hand was kept in a heated pad for at least
5 min before and during blood sampling. The ECG was recorded with precordial electrodes, and arterial blood pressure was measured by the indirect auscultatory method.

After a 2-h tracer equilibration period the breakfast meal was served. On CD and ED it contained $29 \mathrm{~kJ} / \mathrm{kg}$ body weight (56\% carbohydrate (CHO), 30\% fat, $14 \%$ protein). On DD the breakfast meal was reduced in calories with an amount equivalent to the carbohydrate and the fat expenditure measured during the $45 \mathrm{~min}$ of exercise on ED in excess of expenditure during the corresponding period on $\mathrm{CD}$. These expenditures were assessed by indirect calorimetry. Hence, DD had to follow the other experimental days. On DD breakfast contained $18.5 \pm 1.9 \mathrm{KJ} / \mathrm{kg}$ body weight. Intake of breakfast was completed within $20 \mathrm{~min}$. Four hours after start of breakfast a lunch meal was served $(59 \mathrm{~kJ} / \mathrm{kg}$ body weight, $53 \%$ carbohydrate $(\mathrm{CHO}), 31 \%$ fat, $16 \%$ protein), identical on $\mathrm{CD}, \mathrm{ED}$ and DD. During the equilibration period and until $4 \mathrm{~h}$ after serving the lunch meal, blood was sampled at intervals. Urine was collected and the volume measured immediately after the subjects arrival to the laboratory, before breakfast and lunch, and $4 \mathrm{~h}$ after lunch. Urine for determination of urea was stored immediately at $-20^{\circ} \mathrm{C}$. Expiratory gas was collected in Douglas bags over 5 min at 15 min before breakfast and at 35, 65, 85 and 230 min after start of both breakfast and lunch. The subjects had breathed through the mouth-piece $3 \mathrm{~min}$ in advance.

On CD the subjects remained inactive in the bed during the study. On ED 45 min after the start of breakfast the subjects exercised on an ergometer bicycle for $45 \mathrm{~min}$ at a load previously determined to require about $50 \%$ of individual $\dot{\mathrm{V}}_{\mathrm{O}_{2}} \max$. Expiratory gas was collected in Douglas bags at 20 and $40 \mathrm{~min}$ after start of exercise. At rest $\dot{\mathrm{V}}_{\mathrm{O}_{2}}$ was $3.0 \pm 0.12 \mathrm{ml} \cdot \mathrm{kg}^{-1}$. $\mathrm{min}^{-1}$ and increased to $15.5 \pm 1.2 \mathrm{ml} \cdot \mathrm{kg}^{-1} \cdot \mathrm{min}^{-1}$ during exercise corresponding to $53 \pm 2 \% \dot{\mathrm{V}}_{\mathrm{O}_{2}} \max$.

Blood sampling. Blood was sampled from the heated hand vein into iced glass tubes. Blood for determination of glucose, lactate, glycerol, non-esterified fatty acids (NEFA), urea and haematocrit (Hct) was stabilized with $10 \mathrm{IU}$ heparin $/ \mathrm{ml}$ blood. Blood for determination of insulin and C-peptide was stabilized with 500 kallikrein inhibitory units aprotinin (Transylol, Bayer, Leverkusen, Germany) and $1.5 \mathrm{mg}$ EDTA $/ \mathrm{ml}$ blood. Blood for determination of catecholamines was stabilized with $5 \mu \mathrm{mol}$ ethylene glycol-bis-( $\beta$-aminoethyl ether $)-\mathrm{N}, \mathrm{N}$, $\mathrm{N}^{\prime}, \mathrm{N}^{\prime}$-tetraacetic acid (EGTA) and $4 \mu \mathrm{mol}$ reduced gluthatione in $20 \mu \mathrm{l} 0.6 \mathrm{~N}$ sodium hydroxide/ml blood. After sampling blood was immediately centrifuged at $4{ }^{\circ} \mathrm{C}$ and plasma was stored at $-20^{\circ} \mathrm{C}$ or at $-80^{\circ} \mathrm{C}$ (for catecholamine and NEFA determinations) until analysis.

A nalytic procedures and calculations. All glucose and lactate analyses were done immediately after plasma separation by the fixed glucose oxidase and lactate oxidase method using an automatic glucose analyzer (YSI model 2300 STAT PLUS Yellow Springs Instruments, Yellow Springs, Ohio, USA). For the assay of $3-\left[{ }^{3} \mathrm{H}\right]$ glucose radioactivity $2 \mathrm{ml}$ plasma samples were immediately deproteinized with $1 \mathrm{ml} 1 \mathrm{~N}$ perchloric acid. Duplicate aliquots $(500 \mu \mathrm{l})$ of the supernatant were evaporated under a stream of dry air to remove tritiated water. The dry residue was dissolved in $200 \mu$ l water and counted with $3 \mathrm{ml}$ scintillation liquid (Ultimate Gold; Packard Instruments, Ulgersmaveg, Groningen, The Netherlands) in a liquid scintillation spectrometer. The glucose pool (distributions space plasma concentration) as well as the rates of appearance ( $\mathrm{Ra})$ and disappearance $(\mathrm{Rd})$ of glucose in the basal state, in which the plasma glucose concentration was constant, were calculated from values of plasma glucose specific activity between 60 and $120 \mathrm{~min}$ by the extrapolation procedures described by 
Steele et al. [9]. In non-steady-state glucose kinetics were determined according to a modified single compartment analysis assuming that the pool fraction in which rapid changes in concentration and specific activity of glucose take place is 0.65 [10]. A sliding fit technique employing three consecutive glucose or specific activity values was used to minimise the fluctuations caused by random errors in the determination of these variables [10].

Commercially available radioimmunoassay (RIA) kits (Novo Nordisk, Copenhagen, Denmark) were used for determination of plasma concentrations of insulin and C-peptide by previously described methods $[11,12]$. All samples from one subject were analysed in the same assay run. Catecholamines were assayed by a previously described single-isotope radioenzymatic assay [13]. Concentrations in plasma of NEFA and glycerol were determined by a microfluorometric assay [14] and an enzymatic fluorometric technique [12], respectively. Plasma urea and urine urea concentration was determined spectrophotometrically as previously described [15] after adding the plasma or urine sample to a reagent containing urease (SIGMA kit, Sigma Diagnostics, St. Louis, Missouri, USA). Haematocrit was measured by the microhaematocrit method. Expired air was analysed for $\mathrm{O}_{2}$ and $\mathrm{CO}_{2}$ by paramagnetic (Servomex OA 189, Crowborough, Sussex, United Kingdom) and infrared (Capnograph Godard 146, Bilthoven, The Netherlands) gas meters, respectively, and volume was measured in a $200 \mathrm{~L}$ spirometer.

Incremental areas under the plasma concentration vs time curve (AUC) for glucose, insulin and C-peptide excursions were calculated for 4-h periods by the trapezoid method from the last pre-breakfast (B-AUC) and pre-lunch (L-AUC) values, respectively. Net areas are presented, areas below premeal values having been subtracted from areas above. However, the conclusions were identical to those based on gross incremental areas above premeal values or on overall areas above the $\mathrm{x}$-axis.

Calculations of whole body glucose oxidation and storage, lipid oxidation and lipid synthesis were done according to Mikines et al. [16]. In brief, calculations were based on measurements of $\dot{\mathrm{V}}_{\mathrm{O}_{2}}, \dot{\mathrm{V}}_{\mathrm{CO}_{2}}$ and urinary excretion of urea nitrogen and glucose. Protein combustion was calculated as 100/ 16 . urea nitrogen excretion corrected for changes in the urea pool, assuming a distribution volume for urea of $60 \%$ of body weight.

\section{Statistical analysis}

Statistical evaluation was made by the Kruskal-Wallis test, a non-parametric counterpart to ANOVA, and by non-parametric ranking tests; Wilcoxon's test for paired data, and MannWhitney's test for unpaired data [17]. $p$ value less than 0.05 (2-tailed testing) was considered significant.

\section{Results}

Glucose, insulin and C-peptide responses (Fig. 1). Compared to control experiments exercise interrupted the increase seen in all three variables after start of breakfast and caused a marked decrease in glucose and insulin concentrations $(p<0.05)$. After exercise rebound increases were seen in glucose, insulin and C-peptide concentrations $(p<0.05)$. At 240 min glucose concentrations were at basal levels
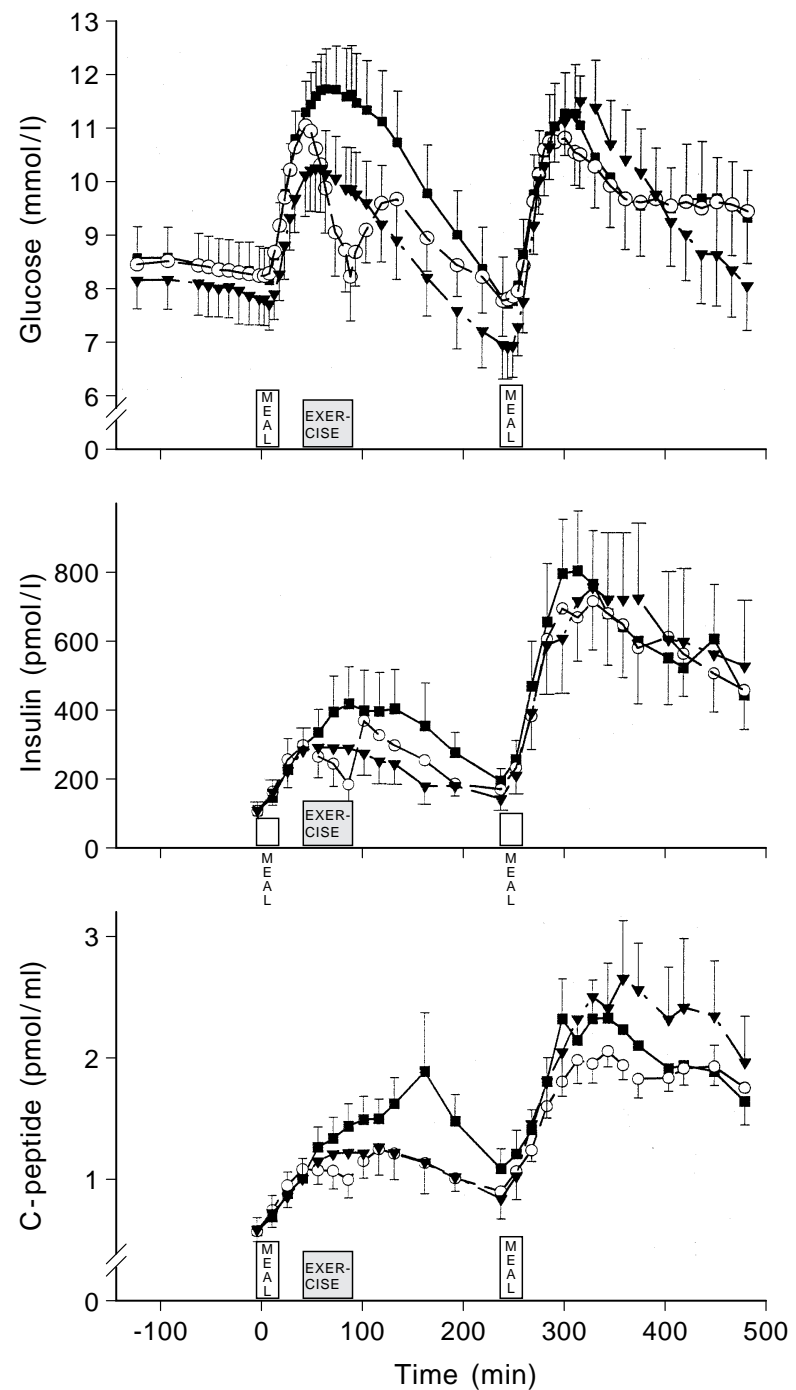

Fig. 1. Plasma glucose, insulin and C-peptide concentrations in NIDDM patients studied on 3 occasions; control day (CD) (ロ) $(n=9)$, exercise day (ED) $(O)(n=9)$ and diet day (DD) $(\boldsymbol{\nabla})(\mathrm{n}=7)$. Breakfast was taken by the subjects at time $0 \mathrm{~min}$, and lunch at time $240 \mathrm{~min}$ on all three days. Exercise on $\mathrm{ED}$ was performed for $45 \min \left(53 \pm 2 \% \dot{\mathrm{V}}_{\mathrm{O}_{2}} \max \right)$ from time $45 \mathrm{~min}$. Values are means \pm SEM

and similar on ED and CD. On the diet day the increases in all three variables after breakfast were attenuated $(p<0.05)$. Confirming that post-breakfast glycaemia and insulin secretion were reduced by both exercise and diminished caloric intake, BAUCs for glucose, insulin and C-peptide were significantly lower on ED and DD compared with CD (Fig.2). Interestingly, B-AUCs on ED and DD did not differ $(p>0.05)$ (Fig. 2). In response to lunch the three variables increased similarly on the three days of experiments (Figs. 1 and 2).

G lucose kinetics. The rate of appearance ( $\mathrm{Ra}$ ) of glucose in plasma increased similarly on CD and ED in response to breakfast intake and this increase was not affected by exercise (Fig. 3). Four subjects had 

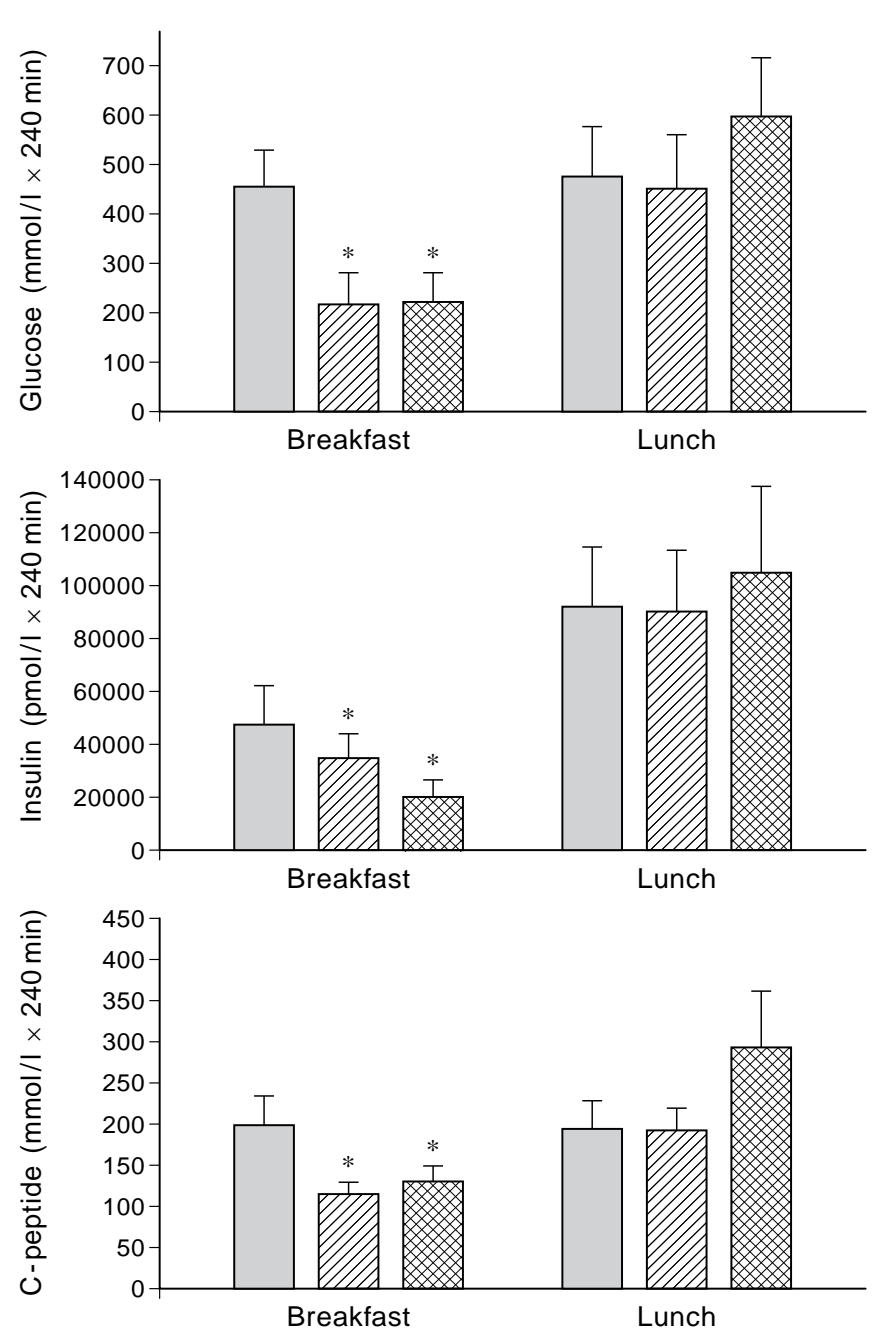

Fig. 2. Area under curve (AUC) for glucose, insulin and Cpeptide in NIDDM patients studied on 3 occasions; control day $(\mathrm{CD})(\mathrm{W})(\mathrm{n}=9)$, exercise day $(\mathrm{ED})(\mathbb{Z})(\mathrm{n}=9)$ and diet day (DD) $(n=7)$. Breakfast AUC (B-AUC) was calculated from time $0 \mathrm{~min}$ to time $240 \mathrm{~min}$. Lunch AUC was calculated from time 240 min. $\mathrm{p}<0.05$, difference in comparison to CD

tracer infused also on DD and in each of these subjects $\mathrm{Ra}$ was lower on DD as compared to $\mathrm{CD}$ throughout the breakfast period (data not shown). In response to breakfast the rate of disappearance of glucose $(\mathrm{Rd})$ increased identically on CD and ED until the time of exercise on ED (Fig. 3). During the exercise period Rd increased $(p<0.01)$ and also the average glucose clearance calculated for the 45-min exercise period was increased compared to $\mathrm{CD}$ $\left(3.05 \pm 0.38\right.$ vs $1.68 \pm 0.17 \mathrm{ml} \cdot \mathrm{min}^{-1} \cdot \mathrm{kg}^{-1}$, respectively, $p<0.05)$. In the period after exercise and until lunch glucose clearance did not differ between ED and CD $\left(1.74 \pm 0.23\right.$ and $1.83 \pm 0.16 \mathrm{ml} \cdot \mathrm{min}^{-1} \cdot \mathrm{kg}^{-1}$, $\mathrm{p}>0.05)$. After lunch both $\mathrm{Ra}$ and $\mathrm{Rd}$ did not differ between experimental days.

L actate responses. (Fig.4). Following both breakfast and lunch meals lactate concentrations changed in
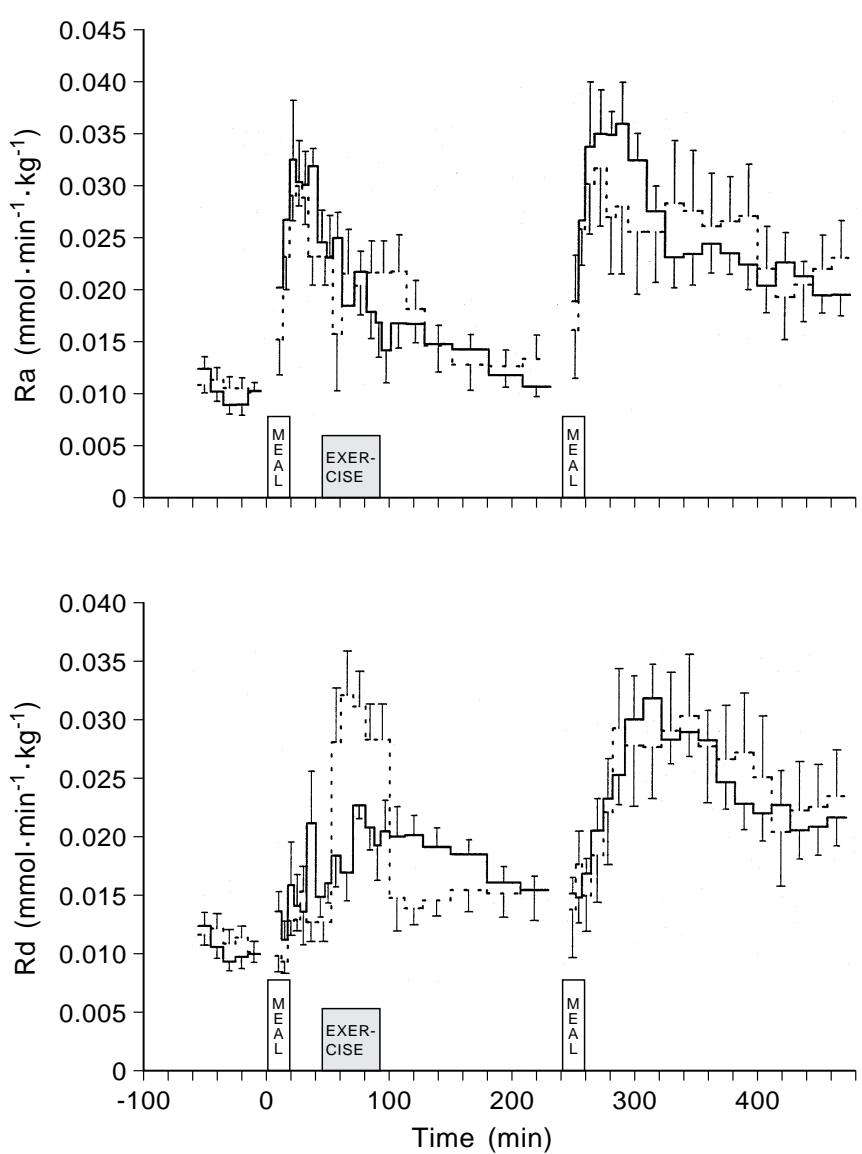

Fig. 3. Rate of appearance ( $\mathrm{Ra}$ ) and rate of disappearance (Rd) of plasma glucose in 9 NIDDM patients both on control Day (CD) (-)and exercise day (ED) (- - - ). Breakfast was taken by the subjects at time $0 \mathrm{~min}$, and lunch at time $240 \mathrm{~min}$ on both days. Exercise on ED was performed for $45 \min (53 \pm 2 \%$ $\dot{\mathrm{V}}_{\mathrm{O}_{2}}{ }^{\text {max }}$ ) from time $45 \mathrm{~min}$. Values are means $\pm \mathrm{SEM}$

parallel with glucose concentrations except during the 45 min of exercise where lactate concentration increased above concentrations in control experiments $(p<0.05)$. Consequently, B-AUCs for lactate were significantly lower on DD as compared to both CD and ED $(21 \pm 15,107 \pm 27$ and $113 \pm 36 \mathrm{mmol} / \mathrm{l}$. $240 \mathrm{~min}$, respectively, $p<0.05$ ), while L-AUCs for lactate concentrations were identical during $\mathrm{CD}, \mathrm{ED}$ and DD $(109 \pm 18,103 \pm 18$ and $111 \pm 20 \mathrm{mmol} /$ $1 \cdot 240 \mathrm{~min}$, respectively, $p>0.05)$.

Glycerol and NEFA concentrations (Fig.4). On CD and DD glycerol and NEFA concentrations were similar and varied opposite to those of insulin in response to meals. Exercise counteracted the breakfast-induced decreases in concentrations. Apart from the exercise-induced peak, glycerol and NEFA concentrations were similar on ED compared to DD and CD.

Catecholamine responses. Fasting epinephrine and norepinephrine concentrations were identical on 

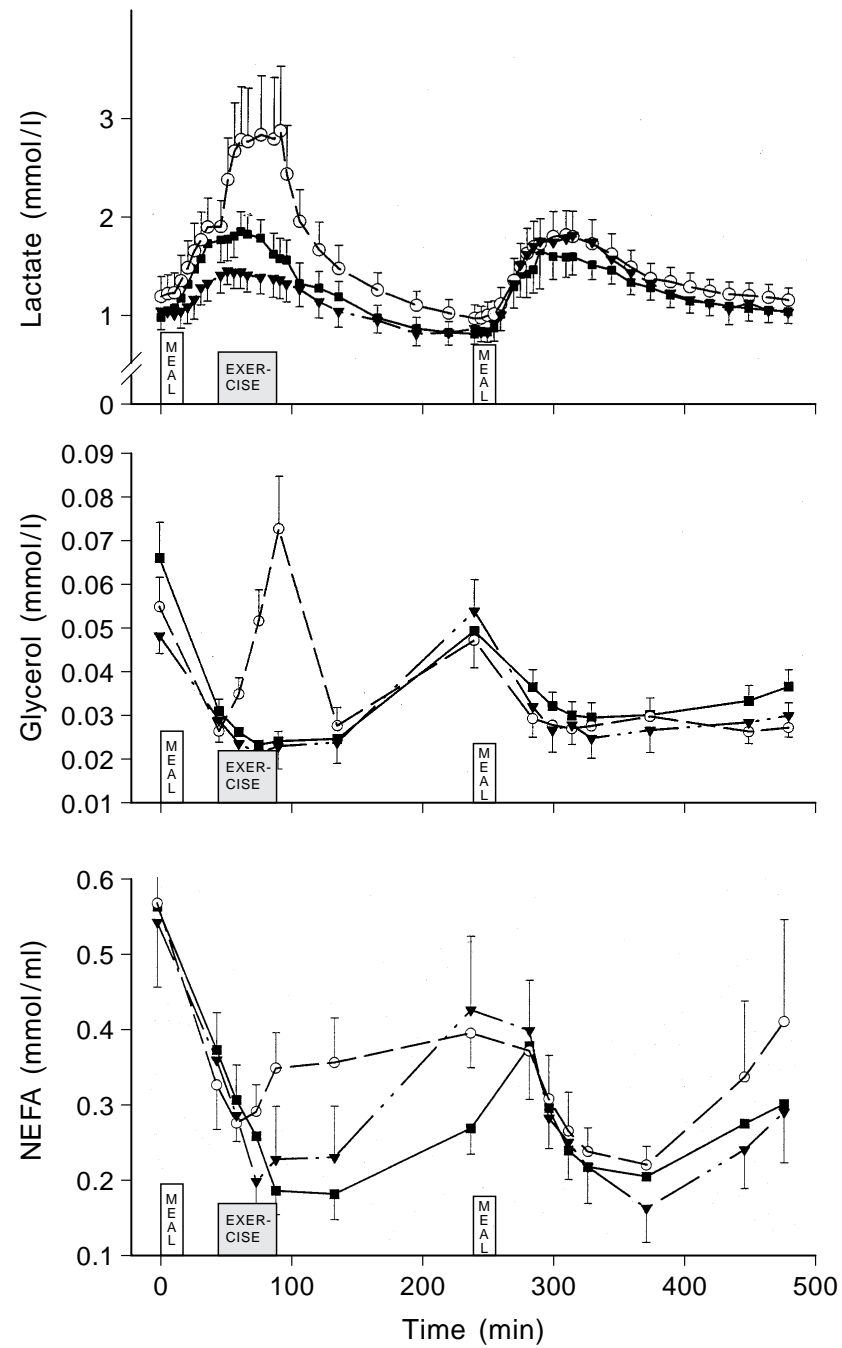

Fig. 4. Plasma lactate, glycerol and NEFA concentrations in NIDDM patients studied on 3 occasions; control day (CD) (Ш) $(n=9)$, exercise day (ED) $(\bigcirc)(n=9)$ and diet day (DD) ( $\boldsymbol{\nabla})(n=7)$. Breakfast was taken by the subjects at time $0 \mathrm{~min}$, and lunch at time $240 \mathrm{~min}$ on all 3 days. Exercise on ED was performed for $45 \min \left(53 \pm 2 \% \dot{\mathrm{V}}_{\mathrm{O}_{2}} \max \right)$ from time $45 \mathrm{~min}$. Values are means \pm SEM

$\mathrm{CD}, \quad \mathrm{ED}$ and $\mathrm{DD}(0.14 \pm 0.02,0.13 \pm 0.02$ and $0.12 \pm 0.02, \mathrm{nmol} / \mathrm{l}$, and $1.2 \pm 0.1,1.1 \pm 0.1$ and $1.3 \pm 0.7 \mathrm{nmol} / \mathrm{l}$, respectively). On CD and DD catecholamine concentrations were constant throughout the study. On ED both epinephrine and norepinephrine increased significantly in response to exercise and at 90 min were higher $(p<0.05)$ than on both $\mathrm{CD}$ and DD (epinephrine: $0.22 \pm 0.03 \mathrm{nmol} / \mathrm{l}$; norepinephrine: $5.03 \pm 0.68 \mathrm{nmol} / \mathrm{l})$.

Oxidation data. Throughout the study glucose, lipid and protein oxidation rates were similar between the 3 days of investigation except during the $45 \mathrm{~min}$ of exercise on ED. During exercise oxidation of carbohydrate and lipid increased from $0.16 \pm 0.03$ and $0.05 \pm 0.01 \mathrm{~g} / \mathrm{min}$, respectively, to $1.07 \pm 0.12$ and
$0.23 \pm 0.02 \mathrm{~g} / \mathrm{min}$, respectively. Protein oxidation was unaffected by exercise. In the period after exercise and before lunch glucose oxidation was $0.15 \pm 0.02 \mathrm{~g} /$ min and did not differ $(p>0.05)$ from values on $C D$ and DD $(0.13 \pm 0.03$ and $0.12 \pm 0.02 \mathrm{~g} / \mathrm{min}$, respectively).

\section{Discussion}

Hyperglycaemia is an important pathogenic determinant of reversible symptoms associated with NIDDM. Furthermore, hyperglycaemia as well as hyperinsulinemia is involved in the development of long-term complications inherent in this disease [18, 19]. Accordingly, a therapeutic strategy is to lessen increased glucose and insulin levels. Previous studies have shown that in the fasting state moderate exercise may acutely reduce glucose and insulin concentrations in NIDDM patients [2] whereas heavy exercise may deteriorate glucose homeostasis [20]. The present study aimed at elucidating the influence of exercise taken during conditions mimicking everyday life. A major finding was that a 45-min bicycle ride of moderate intensity taken after breakfast attenuates postprandial hyperglycaemia and hyperinsulinaemia in patients with mild NIDDM.

The rate of appearance of glucose in plasma increased in response to meals and the increase was not affected by exercise (Fig. 3). The latter finding is probably not a consequence of weaknesses inherent in the applied isotopic tracer method. Thus, it has been concluded that while absolute rates may be underestimated the method nevertheless allows qualitative evaluation of changes in glucose production [21]. In agreement with this we have recently compared the isotope dilution technique with the arterio-hepatic venous balance method in healthy, postabsorptive subjects and found identical relative increases in glucose production in response to exercise (unpublished data). The finding of no change in glucose production in response to exercise in the postprandial state is in line with the facts that often an increase in hepatic glucose production is not seen with exercise when insulin levels are elevated $[1,7,22,23]$ and that exercise does not change glucose absorption from the gut [24]. In contrast to our findings, glucose production has recently been found to increase normally during exercise in NIDDM patients [5]. However, in that study patients were in the postabsorptive state and insulin levels always tended to decrease below basal levels during exercise whereas in the present study concentrations were increased by breakfast and remained above basal levels throughout the exercise period.

The rate of disappearance of glucose was markedly enhanced during exercise and consequently the plasma glucose concentration decreased (Figs. 1 and 
$3)$. The exercise-induced increase in glucose clearance has in healthy, postabsorptive subjects been ascribed to increases in blood flow, glucose transport and oxidation in the working muscles $[7,25]$. In the present study, in response to exercise carbohydrate oxidation increased from $0.120 \pm 0.005$ to $1.069 \pm 0.039 \mathrm{~g} / \mathrm{min}$, the increase being equivalent to $53.4 \pm 5.7 \%$ of the carbohydrate eaten during breakfast. In line with the present finding of a glucose lowering effect in the postprandial state, exercise has previously been shown to enhance the oxidation of an oral glucose load in healthy subjects [26, 27].

In the period after exercise and before lunch overall glucose disappearance and oxidation of glucose did not differ significantly from findings in control experiments. Compared to findings in control experiments, after exercise glucose clearance was also not changed even though the mean insulin concentration was reduced (Fig. 1) $(p<0.05)$. The mechanism for this may include enhancement of both non-insulin and insulin-mediated glucose transport and disposal $[28,29]$.

Exercise reduced overall post-breakfast insulin secretion as indicated by attenuated increases in plasma insulin and C-peptide concentrations in experiments with compared to experiments without exercise (Fig. 2). This effect probably mainly reflected diminished pancreatic beta-cell stimulation secondary to the reduction in plasma glucose concentrations. In addition, during exercise beta-cell secretion was probably depressed by increased sympathetic nerve activity [7]. This supposition is supported by the fact that both epinephrine and norepinephrine concentrations in plasma increased during exercise and that the rebound increase in plasma insulin seen immediately after exercise peaked earlier than the rebound increase in plasma glucose (Fig. 1).

Another major finding in the present study was that a reduction in energy intake during breakfast had exactly the same overall effect on postprandial glucose and insulin responses as an equivalent exercise-induced increase in energy expenditure (Figs.1 and 2). However, the underlying mechanisms differed. The attenuated increase in plasma glucose concentrations in experiments with reduced caloric intake compared to control experiments reflected a lower rate of appearance of glucose in the former. The fact that insulin secretion was lessened after breakfast in diet compared to control experiments can partly be ascribed to a lower stimulation by plasma glucose in diet experiments. However, probably an attenuated stimulation by gut factors in consequence to the reduced glucose load to the gut also contributed as insulin and glucose responses were reduced identically in diet compared with exercise experiments even though adrenergic beta-cell suppression was only present during exercise. The importance of gut-incretins is indicated by the finding that in control experiments a higher energy intake with lunch compared to breakfast was accompanied by higher integrated 4-h insulin and C-peptide responses in the face of identical plasma glucose responses (Fig. 1).

The present findings also add significantly to our understanding of insulin regulation in exercise. Compared to control experiments overall morning insulin secretion was reduced identically in diet and exercise experiments. In the two latter experiments a given fraction of the energy intake administered in control experiments was withheld or combusted, respectively. These findings indicate that insulin secretion is closely matched to the net energy load on the body. Compared to control conditions with the same energy intake, during exercise the various mechanisms influencing insulin secretion serve to reduce the secretion exactly corresponding to the amount of insulin which would be necessary to dispose of an amount of substrates equivalent to the extra energy used during exercise. In line with the present findings we have previously found the same 24 -h integrated insulin secretion and plasma glucose concentration in athletes and healthy sedentary subjects, the former subjects having both a much higher daily energy intake and output than the latter [30]. It appears that in terms of reducing insulin secretion and glucose levels acute exercise has no effect beyond that of increasing energy expenditure. The therapeutic implication is that the diabetic patient can choose between eating abundantly and subsequently burning the excess calories or simply eat less.

In the present study responses of glucose, insulin and C-peptide to a standardised lunch were similar in exercise, diet and control experiments (Figs. 1 and 2). It might have been expected that exercise taken after breakfast would have affected glucose clearance also during the subsequent lunch. However, exerciseinduced enhancement of glucose clearance in the post exercise period is closely related to the depletion of muscle glycogen during exercise [28, 29, 31], and it wanes as glycogen stores are replenished by food intake [31]. The intensity and duration of exercise applied in the present study would even in the fasting state have been expected to result in only modest muscle glycogen breakdown. Furthermore, it is known that supply of exogenous glucose diminishes glycogen breakdown during exercise [7, 32] and enhances glycogen replenishment after exercise [33, 34]. In accordance with the view that only little, if any, muscle glycogen depletion took place during the morning of the exercise day, the integrated carbohydrate oxidation corresponded to $435 \pm 13 \mathrm{mmol}$ while integrated tissue glucose uptake was $394 \pm 27 \mathrm{mmol}$. Furthermore, the $480 \pm 16 \mathrm{mmol}$ glucosyl units contained in the breakfast would suffice to fully compensate for any oxidation of endogenous carbohydrate.

In accordance with these considerations, after exercise neither glucose clearance nor insulin 
concentrations were altered when measured just before lunch and compared to values in control experiments (Fig. 1). In contrast to our findings one study of IDDM patients did demonstrate a lowering effect of postprandial exercise on glucose responses during a subsequent meal [35]. However, in contrast to our patients, who were able to spontaneously reduce insulin secretion in response to exercise, these patients had the same plasma insulin levels whether they exercised or not. Another study of IDDM diabetic patients found no reduction by postprandial exercise in glucose responses to a subsequent meal whether or not the morning insulin dose was reduced [6].

In conclusion, the present study has shown that exercise-induced energy expenditure reduces postprandial glucose and insulin responses in patients with mild NIDDM. An equivalent reduction in energy intake has the same overall effect on these variables. Neither postprandial exercise to an extent realistic in the treatment of NIDDM patients nor meal reduction influences glucose and insulin responses to a subsequent meal.

A cknowledgements. The authors thank Ms. L. Kall, Ms. V. Staffeldt, Ms. R. Kraunsøe and Ms. G. Hau for skilled technical assistance. The assistance of clinical dietician Birgitte Stilling, Rigshospitalet, in the preparation of the meals is gratefully acknowledged. Financial support was received from the Danish Diabetes Association, the Weimann Foundation and the Danish National Research Foundation (I.nr.SSVF 12-9360).

\section{References}

1. Minuk HL, Vranic M, Marliss EB, Hanna AK, Albisser AM, Zinman B (1981) Glucoregulatory and metabolic response to exercise in obese noninsulin-dependent diabetes. Am J Physiol 240:E458E464

2. Koivisto VA, DeFronzo RA (1984) Exercise in the treatment of type II diabetes. Acta Endocrinol [Suppl] 262: 107-111

3. Hubinger A, Franzen A, Gries FA (1987) Hormonal and metabolic response to physical exercise in hyperinsulinemic and non-hyperinsulinemic type 2 diabetics. Diab Res Clin Exp 4: 57-61

4. Devlin JT, Hirshman M, Horton ED, Horton ES (1987) Enhanced peripheral and splanchnic insulin sensitivity in NIDDM men after single bout of exercise. Diabetes 36: 434-439

5. Martin IK, Katz A, Wahren J (1995) Splanchnic and muscle metabolism during exercise in NIDDM patients. Am J Physiol 269:E583E590

6. Hubinger A, Ridderskamp I, Lehmann E, Gries FA (1985) Metabolic response to different forms of physical exercise in type I diabetics and the duration of the glucose lowering effect. Eur J Clin Invest 15: 197-203

7. Galbo H (1983) Hormonal and metabolic adaptions to exercise. Thieme, Stuttgart New York

8. Hother-Nielsen O, Beck-Nielsen H (1990) On the determination of basal glucose production rate in patients with type 2 (non-insulindependent) diabetes mellitus using primed-continuous 3-3H-glucose infusion. Diabetologia 33: 603-610

9. Steel R, Wall JS, De Bodo RC, Altszuler N (1956) Measurement of size and turnover rate of body glucose pool by the isopope dilution method. Am J Physiol 187: 15-24

10. Radziuk J, Norwich KH, Vranic M (1978) Experimental validation of measurements of glucose turnover in nonsteady state. Am J Physiol 234:E84-E93
11. Heding LG (1975) Radioimmunological determination of human C-peptide in serum. Diabetologia 11: 541-548

12. Galbo H, Holst JJ, Christensen NJ (1979) The effect of different diets and of insulin on the hormonal response to prolonged exercise. Acta Physiologica Scandinavica 107: 19-32

13. Ben-Jonathan N, Porter JC (1976) A sensitive radioenzymatic assay for dopamine, norepinephrine, and epinephrine in plasma and tissue. Endocrinology 98: 1497-1507

14. Miles J, Glasscock R, Aikens J, Gerich J, Haymond M (1983) A microfluorometric method for the determination of free fatty acids in plasma. J Lipid Research 24: 96-99

15. Dela F, Mikines KJ, Von Linstow M, Galbo H (1991) Effect of training on response to a glucose load adjusted for daily carbohydrate intake. Am J Physiol 260:E14-E20

16. Mikines KJ, Farrell PA, Sonne B, Tronier B, Galbo H (1988) Postexercise dose-response relationship between plasma glucose and insulin secretion. J Appl Physiol 64: 988-999

17. Siegel S (1956) Nonparametric statistics for the behavorial sciences. McGraw-Hill, New York

18. Fontbonne A, Eschwege E (1987) Diabetes, hyperglycaemia, hyperinsulinaemia and atherosclerosis: epidemiological data. Diabete Metab 13: 350-353

19. West KM, Ahuja MM, Bennett PH, et al (1982) Interrelationships of microangiopathy, plasma glucose and other risk factors in 3583 diabetic patients: a multinational study. Diabetologia 22: 412-420

20. Kjaer M, Hollenbeck CB, Frey-Hewitt B, Galbo H, Haskell W, Reaven GM (1990) Glucoregulation and hormonal responses to maximal exercise in non-insulin-dependent diabetes. J Appl Physiol 68: 2067-2074

21. Coggan AR (1991) Plasma glucose metabolism during exercise in humans. [Review]. Sports Medicine 11: 102-124

22. Zinman B, Murray FT, Vranic M, et al. (1977) Glucoregulation during moderate exercise in insulin treated diabetics. J Clin Endocrinol Metab 45: 641-652

23. Jenkins AB, Furler SM, Bruce DG, Chisholm DJ (1988) Regulation of hepatic glucose output during moderate exercise in non-insulindependent diabetes. Metabolism 37: 966-972

24. Fordtran JS, Saltin B (1967) Gastric emptying and intestinal absorption during prolonged severe exercise. J Appl Physiol 23: 331335

25. Dela F, Mikines KJ, Sonne B, Galbo H (1994) Effect of training on interaction between insulin and exercise in human muscle. J Appl Physiol 76: 2386-2393

26. Pirnay F, Scheen AJ, Gautier JF, Lacroix M, Mosora F, Lefebvre PJ (1995) Exogenous glucose oxidation during exercise in relation to the power output. International Journal of Sports Medicine 16: 456-460

27. Ahlborg G, Bjorkman O (1987) Carbohydrate utilization by exercising muscle following pre-exercise glucose ingestion. Clinical Physiology 7: 181-195

28. Zorzano A, Balon TW, Goodman MN, Ruderman NB (1986) Glycogen depletion and increased insulin sensitivity and responsiveness in muscle after exercise. Am J Physiol 251:E664-E669

29. Richter EA, Garetto LP, Goodman MN, Ruderman NB (1984) Enhanced muscle glucose metabolism after exercise: modulation by local factors. Am J Physiol 246:E476-E482

30. Dela F, Mikines KJ, Von Linstow M, Galbo H (1991) Twenty-fourhour profile of plasma glucose and glucoregulatory hormones during normal living conditions in trained and untrained men. J Clin Endocrinol Metab 73: 982-989

31. Ivy JL, Frishberg BA, Farrell SW, Miller WJ, Sherman WM (1985) Effects of elevated and exercise-reduced muscle glycogen levels on insulin sensitivity. J Appl Physiol 59: 154-159

32. Constable SH, Young JC, Higuchi M, Holloszy JO (1984) Glycogen resynthesis in leg muscles of rats during exercise. Am J Physiol 247:R880-R883

33. Ivy JL, Katz AL, Cutler CL, Sherman WM, Coyle EF (1988) Muscle glycogen synthesis after exercise: effect of time of carbohydrate ingestion. J Appl Physiol 64: 1480-485

34. Maehlum S, Felig P, Wahren J (1978) Splanchnic glucose and muscle glycogen metabolism after glucose feeding during postexercise recovery. Am J Physiol 235:E255-E260

35. Caron D, Poussier P, Marliss EB, Zinman B (1982) The effect of postprandial exercise on meal-related glucose intolerance in insulin-dependent diabetic individuals. Diabetes Care 5: 364-369 